УДК $630 * 37$

DOI: $10.34220 / 2311-8873-2020-3-3-57-79$

РЕЗУЛЬТАТЫ АНАЛИЗА ОСНОВНЫХ ПРИЧИН НЕДОСТАТОЧНОЙ

ЭФФЕКТИВНОСТИ ИСПОЛЬЗОВАНИЯ ОТЕЧЕСТВЕННОГО ЛЕСОВОЗНОГО АВТОМОБИЛЬНОГО ТРАНСПОРТА В СОВРЕМЕННЫХ УСЛОВИЯХ ЛЕСОЗАГОТОВИТЕЛЬНОГО ПРОИЗВОДСТВА

Посметьев В.И., Никонов В.О.

Федеральное государственное бюджетное образовательное учреждение высшего образования «Воронежский государственный лесотехнический университет им. Г.Ф. Морозова»

Email: $\underline{8888 \text { nike8888@ mail.ru }}$

Аннотация: В статье подробно рассмотрены причины недостаточной эффективности использования отечественного лесовозного автомобильного транспорта при вывозке лесоматериалов по лесовозным дорогам. Выделены основные технологические процессы и операции, свойства и факторы, при которых проявляется недостаточная эффективность функционирования лесовозного автомобильного транспорта в современных условиях лесозаготовительного производства. Предложены перспективные пути повышения эффективности функционирования лесовозного автомобильного транспорта.

Ключевые слова: отечественный лесовозный автомобильный транспорт, причины недостаточной эффективности, пути повышения, лесовозная дорога, рекуперация энергии, современные условия лесозаготовительного производства.

\title{
THE RESULTS OF ANALYSIS OF THE MAIN CAUSES OF INSUFFICIENT EFFICIENCY OF THE USE OF DOMESTIC FOREST TRANSPORT IN THE MODERN CONDITIONS OF FORESTRY PRODUCTION
}

Posmetev V.I., Nikonov V.O.

Federal State Budgetary Educational Institution of Higher Education «Voronezh State Forestry University. G.F. Morozova»

Email: 8888nike8888@ mail.ru

Summary: The article discusses in detail the reasons for the insufficient efficiency of the use of domestic timber road transport when transporting timber on timber roads. The main technological processes and operations, properties and factors under which the insufficient efficiency of the functioning of timber road transport in modern conditions of logging production is manifested are highlighted. Prospective ways of increasing the efficiency of functioning of timber road transport are proposed.

Keywords: domestic timber road transport, reasons for insufficient efficiency, ways of increasing, timber road, energy recovery, modern conditions of logging production. 


\section{Введение}

Леса занимают почти третью часть земной поверхности и играют важную роль в жизни и деятельности человека. Лесопромышленный комплекс нашей страны, в которой сосредоточено четвертая часть всех мировых запасов древесины, имеет огромный природный и производственный потенциал. Являясь составной частью экономического потенциала России, лесные ресурсы выступают в роли базы развития всех отраслей лесопромышленного комплекса и страны в целом [1].

В современных условиях одной из составляющих успешной работы отечественных лесозаготовительных предприятий, занятых заготовкой и вывозкой лесоматериалов потребителям, является эффективность функционирования и технический уровень использования лесовозного автомобильного транспорта (ЛАТ) с погрузочно-разгрузочными средствами. В настоящее время многие отечественные модели ЛАТ и погрузочно-разгрузочные средства для них все еще далеки от совершенства, так как по ряду параметров не в полной мере отвечают современным требованиям и во многом уступают зарубежным аналогам. Кроме этого, недостаточная эффективность функционирования ЛАТ все еще является важнейшей нерешенной проблемой лесозаготовительного производства. Это приводит к следующим негативным последствиям: снижению скорости вывозки лесоматериалов, увеличению транспортных затрат, повышению времени простоя под погрузкой и разгрузкой, снижению объема вывозимых лесоматериалов, уменьшению производительности, увеличению расхода топлива, возрастанию порожнего пробега и отрицательного влияния на окружающую среду. Также недостаточно эффективное использование ЛАТ нередко становится причиной убыточности лесозаготовительных предприятий, что негативно сказывается на их экономике [2-5].

Выявление основных причин недостаточной эффективности функционирования ЛАТ, а также определение перспективных путей ее максимального повышения на современном этапе развития лесопромышленного комплекса, является важной актуальной задачей, требующей ее решения на основе системного подхода с учетом всей совокупности многочисленных и противоречивых факторов.

\section{Цель исследования}

Целью исследования является анализ доступного научного материала в области основных причин недостаточной эффективности работы отечественных ЛАТ, а также обоснование перспективных направлений их функционирования при движении по лесовозным дорогам (ЛД).

\section{Материал и методы исследования}

Исследование выполнено на основании изучения имеющейся научной литературы российских ученых, занимающихся оценкой эффективности функци- 
онирования ЛАТ.

\section{Результаты исследования и их обсуждение}

Изучение и анализ болышого количества известных российских литературных источников, позволили выявить основные возможные причины недостаточной эффективности функционирования ЛАТ. Укрупненно эти причины имеют связь со следующими основными группами факторов: процессами проектирования, изготовления и производства ЛАТ; их конструктивным совершенством; эксплуатационными и потребительскими свойствами ЛАТ; применяемыми при вывозке лесоматериалов технологиями и методами; состоянием, функционированием и месторасположением производственно-технической и материально-технической баз; техническим состоянием ЛАТ, с используемыми технологиями и качеством организации ТО, ТР и диагностирования; условиями эксплуатации; квалификацией водителей и ремонтного персонала; рациональным формированием подвижного состава ЛАТ; процессами восстановления работоспособного состояния его агрегатов и систем.

Рассмотрим более подробно связь перечисленных факторов с причинами недостаточной эффективности функционирования ЛАТ с учетом современного состояния лесозаготовительного производства.

На эффективность функционирования ЛАТ оказывают влияние процессы, связанные с его проектированием. В процессе проектирования новых и совершенствования существующих конструкций ЛАТ решаются естественно возникающие противоречия между предъявляемыми к ним производственными и эксплуатационными требованиями, обусловленные ухудшением одних требований при улучшении других. Поэтому для оптимального удовлетворения возрастающих потребностей лесозаготовительного производства в новых эффективных конструкциях ЛАТ при их комплексном проектировании необходимо обеспечивать высокую прогрессивность конструкции, удовлетворяющую повышенным требованиям потребителя и во многом зависящую от их конструктивности, надежности, производительности, технологичности, экономичности и эстетичности.

Прогрессивность новой конструкции ЛАТ ухудшается при его низких значениях технико-экономических показателей, нерациональном усложнении и увеличении массы, некомплектности и нецелесообразной компоновке с разделением на сборочные единицы и узлы, а также при повышении стоимости производства ЛАТ. Технический уровень при конструировании ЛАТ снижается по следующим причинам: поверхностном и не критическом анализе существующих аналогичных конструкций ЛАТ; рассмотрении в процессе проектирования не всех возможных вариантов конструкций ЛАТ и выбора из них не самого оптимального; применении оригинальных узлов и деталей, нерациональных способах агрегатирования; 
недостаточные широта и глубина всесторонних исследований в области используемых конструкций агрегатов и материалов; отсутствии спроектированных узлов ЛАТ в форме независимых модулей, устанавливаемых в собранном виде на ЛАТ; снижении циклических прочностных свойств деталей, придания им неоптимальной формы, способствующей возникновению в их конструкции концентраторов напряжений; отсутствии в конструкции узлов, эффективно снижающих воздействие циклических и динамических нагрузок, а также деталей из различных видов пластмасс, обладающих в сравнении с металлическими сплавами низкой плотностью, высокими значениями антикоррозионной стойкости и пластичности.

Надежность проектируемой конструкции ЛАТ понижается при: снижении его эксплуатационных свойств; точности функционирования в различных условиях эксплуатации; ухудшении долговечности и безопасности, а также усложнении процессов монтажа, ТО и ТР. Технологичность значительно ухудшается при: снижении технологической культуры технологов, занимающихся проектированием новых конструкций ЛАТ; усложнении конструкции ЛАТ; возрастании трудоемкости изготовления, сборки и регулировки сборочных единиц и деталей; отсутствии использования передовых наиболее эффективных технологических процессов и приемственности конструкции ЛАТ в производстве. Экономичность не обеспечивает максимального народнохозяйственного эффекта при наибольших значениях стоимости новой конструкции ЛАТ и расходов на его эксплуатацию. Также улучшение экономичности не может быть достигнуто при: ухудшении экономической культуры конструкторов, отсутствии в работе экономистов, неточном определении технико-экономических показателей и их корректировки при проектировании новой конструкции ЛАТ по минимуму суммарных затрат [6].

Недостаточный уровень эстетичности новой конструкции ЛАТ наблюдается при: несоответствии спроектированной конструкции ЛАТ ее функциям, назначению, выразительности формы, цельности и соразмерности; возникновении сложностей и неудобств в процессе выполнения ТО и ТР ЛАТ; неблагоприятных режимах работы рабочих занятых в ТО и ТР; отсутствии подходящих психологических условий для наиболее эффективного функционирования, а также ухудшении культуры обслуживания ЛАТ. Снижение эффективности ЛАТ наблюдается при несоблюдении предъявляемых в процессе проектирования к ним требований и рекомендаций по соответствию используемого для вывозки лесоматериалов ЛАТ применяемым технологиям заготовки, транспортным, климатическим и дорожным условиям эксплуатации, регулярности и массовости вывозки лесоматериалов, а также специфическим особенностям этого процесса. Также новая конструкция ЛАТ является неэффективной, если не удовлетворяет современным социальным требованиям, заключающимся в обеспечении необходи- 
мых условий труда при оптимальном уровне затрат физической энергии, не обеспечивает повышения производительности процесса, вследствие более рационального расходования материальных, трудовых и денежных ресурсов.

Невыполнение требований при проектировании конструкции ЛАТ, заключающегося в обеспечении ее работоспособности приводит к увеличению затрат времени и материальных средств на осуществление регламентированных ТО и ТР, снижая эффективность функционирования ЛАТ. Также увеличение затрат на выполнение ТО и ТР проектируемого ЛАТ будет проявляться при: не учете всех факторов, а также неправильном нахождении зависимостей между величинами, характеризующими технологию и организацию ТО и ТР; частичном или полном отсутствии материальных и трудовых нормативов на их проведение; использовании методов, не позволяющих с высокой точностью прогнозировать объемы и периодичность выполнения ТО и ТР; неточной оценке эффективности новых проектируемых конструкций ЛАП, обеспечивающих осуществление требований технологии и организации ТО и ТР; отказе от испытаний ЛАТ для оценки уровня удовлетворения требований, предъявляемых к технологии и организации ТО и ТР [7].

От процесса производства ЛАТ, включающего в себя множество различных технологических операций, также зависит последующая эффективность функционирования ЛАТ при использовании его по назначению. При вывозке лесоматериалов ЛАТ по недостаточно обустроенным ЛД, основные узлы и агрегаты ЛАП подвергаются повышенным динамическим нагрузкам. Это обстоятельство приводит при проектировании и производстве ЛАТ к увеличению их массы за счет необходимости повышения запаса прочности, и, следовательно, к снижению грузоподъемности и повышению стоимости ЛАТ. Повышение массы одной детали ЛАТ в процессе их производства приводит к пропорциональному возрастанию массы других его деталей. Дополнительно к этому, повышение массы деталей двигателя и трансмиссии ЛАТ является причиной возрастания появляющихся вибраций, которые приводят к сокращению их надежности. Увеличение массы деталей ЛАТ приводит к увеличению расходов энергии и материалов при их изготовлении, а также затрат в процессе эксплуатации ЛАТ. Достижение высоких показателей надежности в процессе производства ЛАТ зависит от следующих факторов: уровня разработки отдельных технологических операций изготовления деталей ЛАТ, зависящих от корректного выбора типа и материала заготовки, способа ее получения, точности обработки поверхности детали, а также от технологичности конструкции детали, общего количества деталей, изготавливаемых за определенное время в заданном количестве, имеющемся технологическом оборудовании, инструмента, расходных материалов, от типа и способах функционирования производства, а также затрат материальных средств на производственный процесс изготовления. Нестабиль- 
ность технологического процесса изготовления деталей ЛАТ определяется сложной конфигурацией деталей; дефектами, возникающими в процессе механической и термической обработки деталей; низким качеством контрольных операций.

Кроме этого процесс сборки и разборки сборочных единиц ЛАТ, общая доля которого при изготовлении ЛАТ насчитывает 25-30 \% от его общей трудоемкости технологического процесса изготовления, оказывает существенное влияние на надежность работы и долговечность функционирования ЛАТ. Основными причинами, вызывающими снижение надежности является отсутствие применения автоматических процессов сборки, разборки узлов и агрегатов, а также возникающие ошибки в процессе установки деталей и узлов, несоответствие при сборке в соединениях требуемых натягов и зазоров, по причине возникающих при сборке деформаций в сопрягаемых поверхностях. Также в результате повышения долговечности деталей ЛАТ, затраты на их производство увеличиваются, при этом сокращаются затраты на выполнение ремонтных воздействий в процессе их эксплуатации [8].

Недостаточная эффективность ЛАТ также во многом связана с уровнем совершенства конструкций ЛАТ, которое должно обеспечить оперативную, безопасную и высокопроизводительную вывозку лесоматериалов с минимальными затратами. На эффективность функционирования ЛАТ в различных дорожных условиях оказывают влияние следующие его технико-эксплуатационные характеристики: компоновка основных агрегатов и систем, расстояние между кузовом и кабиной, грузоподъемность, вид, нормативный расход, качество используемого топлива и смазочных материалов, полезная длина платформы, мощность двигателя, тип трансмиссии, колесная формула и тип используемых шин, наличие автоматических регуляторов и антиблокировочных приспособлений, расположение центра масс ЛАТ, оснащенность гидроманипулятором, количество осей, маневренность, а также рациональное соотношение масс звеньев ЛАТ по его устойчивости и курсовой управляемости в процессе торможения. Так, ЛАТ с различным количеством приводных осей будут иметь и иную полезную нагрузку, нормативный расход топлива и проходимость. Снижение грузооборота ЛАТ наблюдается при снижении допустимой его габаритной длины путем отсоединения от него одного прицепа значительной длины или нескольких прицепов обычной длины.

Периодичность ТО и ТР относится к одному из важнейших показателей, определяющих конструктивное совершенство ЛАТ и соответствие этой конструкции требованиям эксплуатационной технологичности. Для достижения минимального значения трудоемкости при выполнении ТО и ТР ЛАТ в условиях эксплуатации, его конструкция должна содержать минимальное количество соответствующих воздействий; обладать достаточностью и простотой выпол- 
нения каждой операции по ТО и ТР, с максимальной возможностью без разборочных операций устранять неисправности или отказы; отличаться способностью замены неисправного агрегата или узла с минимальной разборкой других узлов ЛАТ; иметь максимальную унификацию узлов, деталей, крепежных соединений, размеров инструмента, приспособлений, приборов, необходимых для выполнения ТО и ТР, а также минимальную потребность в использовании специализированного инструмента; располагать ограниченной номенклатурой топлив, смазочных материалов, охлаждающих и тормозных жидкостей. Трудоемкость ТО и ТР ЛА зависит от безотказности работы его агрегатов, узлов и деталей, поэтому все конструктивные и технологические мероприятия, повышающие этот показатель, одновременно уменьшают значение трудоемкости выполнения ТО и ТР для поддержания ЛА в исправном состоянии.

Значительное влияние на эффективность процесса транспортирования лесоматериалов ЛАТ оказывают его эксплуатационные свойства. Несоответствие конструктивных особенностей и технического состояния основных агрегатов и систем ЛАТ, функционирующего при вывозке лесоматериалов в различных природно-климатических и дорожных условиях их эксплуатационным свойствам, приводит к значительному снижению эффективности функционирования ЛАТ. Кроме этого выявлено, что наиболее низкими эксплуатационными свойствами обладает такой ЛАТ, который конструктивно менее совершенен, а также имеет более изношенное техническое состояние $[9,10]$.

Важным тягово-скоростным свойством ЛАТ, от которого зависит высокая эффективность вывозки лесоматериалов, является скорость его движения, которая в свою очередь во многом связана с конструктивным совершенством ЛАТ, характеризуемым полной его массой, удельной мощностью двигателя, числом ведущих колес, их радиусом качения, КПД и передаточным числом трансмиссии, значениями аэродинамического сопротивления при высоких скоростях движения. Кроме этого скорость ЛАТ зависит от возможной компоновки автопоезда, сложности дорожных условий вывозки лесоматериалов, характеризуемых внешними факторами, не зависящими от конструкции ЛАТ. Дополнительно к этому на величину скорости ЛАТ оказывает влияние его техническое состояние, динамические качества, ограничение видимости на ЛД, наличие и параметры горизонтальных и вертикальных кривых малого радиуса, крутых подъемов и спусков, геометрические размеры ширины проезжей части, поперечного профиля, обочин ЛД, степень использования грузоподъемности, интенсивность потока транспортных средств на ЛД, частота остановок, особенности вывозимых лесоматериалов, а также профессиональное мастерство водителей ЛАТ [11].

Важной составляющей себестоимости вывозки, во многом определяющей 
эффективность всего процесса вывозки, является расход топлива ЛАТ, зависящий от мощности двигателя. Последняя характеризует динамические свойства ЛАТ и оказывает влияние на его максимальную скорость, производительность, время и путь разгона, а также на возможность преодоления спусков и подъемов с максимальной скоростью. Кроме этого на расход топлива ЛАТ при вывозке лесоматериалов по ЛД на высоких скоростях оказывает влияние сопротивление воздуха, требующее на его преодоление увеличение мощности двигателя. Большая площадь лобовой поверхности кабины ЛАТ и сортиментов, а также отсутствие в его конструкции дефлекторов, закрепляемых на крыше кабины, а также между передней частью полуприцепа и задней стенкой кабины, способствует снижению аэродинамических качеств ЛАТ за счет возникновения между кабиной и полуприцепом значительных по величине турбулентных потоков.

Дополнительно к этому увеличение расхода топлива ЛАТ на 3-4 \% наблюдается при использовании в его конструкции двух вместо одного ведущих мостов. Помимо этого, как правило, неудовлетворительное состояния ЛД приводит к повышению сопротивления качения при движении ЛАТ, и, следовательно, к возрастанию расхода топлива. Кроме этого снижение мощности двигателя ЛАТ и соответственно повышение его расхода топлива наблюдается при вывозке лесоматериалов на местности, изобилующей подъемами и спусками. Также на расход топлива оказывает влияние отсутствие или неудовлетворительная организация движения на ЛД. Кроме всего прочего низкое качество и несоблюдение периодичности выполнения ТО и ТР агрегатов и систем ЛАТ способствует снижению расхода топлива [12].

Наиболее важной и ответственной системой в конструкции ЛАТ является тормозная, которая в свою очередь оказывает существенное влияние на его маневренность, надежность, динамику и безопасность дорожного движения. Данное влияние проявляется в большей степени при вывозке лесоматериалов в сложных дорожных условиях с наличием препятствий на ЛД в виде пней, камней, выходов скальных пород, штабелей заготовленной древесины, порубочных остатков, низкой несущей способности почво-грунтов, которые затрудняют маневрирование и требуют многократных торможений. Присутствующая на ЛД грязь, вода и пыль в процессе торможения ЛАТ попадает на рабочие поверхности тормозных механизмов, приводит к их перегреву, снижению долговечности конструкции и эффективности процесса торможения. Значительным недостатком, снижающим эффективность ЛАТ, является оснащение его недостаточно совершенными конструкциями тягово-сцепных или седельно-сцепных устройств. Это приводит к снижению безопасности их эксплуатации, ухудшению тормозных свойств и уменьшению быстродействия, и синхронизации сра- 
батывания тормозных механизмов, и, как следствие к ухудшению устойчивости ЛАТ и повышению его тормозного пути. При торможении лесовозного автомобиля с прицепом, первыми срабатывают тормозные механизмы лесовозного автомобиля, потом только прицепа. Такое экстренное торможение приводит к появлению существенных усилий сжатия в их тягово-сцепном устройстве, что является причиной потери устойчивости ЛАТ, а также возможного его складывания и опрокидывания [13].

Неудовлетворительная приспособленность ЛАТ к движению по недостаточно обустроенным ЛД, на которых приходится преодолевать разнообразные дефекты и препятствия в виде пней, камней, рвов и валунов с постоянной скоростью движения и достаточной силы тяги, также являются причинами ухудшения эффективности функционирования ЛАТ. Эти причины имеют прямую связь с геометрической, опорной и профильной проходимостью ЛАТ, обеспечивающей возможность преодоления им различных препятствий. Низкие значения тягово-сцепных свойств ЛАТ, а также несоответствующие опорные свойства грунтов в большинстве случаев являются причинами потери проходимости ЛАТ. Последнее наблюдается при ухудшении опорных свойств, определяемых давлением колес ЛАТ на грунт и величиной создаваемой колесом колеи. В случае повышения удельного давления на лесную почву, колесо начинает утопать и погружаться в почву, создавая колею, глубина которой возрастает с увеличением количества проездов ЛАТ. Ухудшение профильной проходимости ЛАТ прослеживается при его несоответствующих значениях углов переднего и заднего свесов, углов складывания в горизонтальной и вертикальной плоскостях полурам, баз и дорожного просвета.

Неправильный выбор конструктивных параметров ЛАТ для требуемых условий вывозки лесоматериалов, нерациональное определение его колесной формулы, а также сцепного веса всех прицепных звеньев с лесоматериалами, приводит к существенному ограничению его проходимости для заданных условий эксплуатации. Отказ от использования коэффициента сцепного веса ЛАТ, определяемого отношением его полного веса и нагрузкой на ведущий мост приведет в процессе въезда ЛАТ на подъем при вывозке лесоматериалов в плохих дорожных условиях к снижению его ходовых качеств. Значительное снижение проходимости ЛАТ, приводит к уменьшению его скорости, буксованию и застреванию, а также к повышению расхода топлива. Все это способствует снижению производительности ЛАТ с колесными формулами $4 \times 2$ или $6 \times 2$.

Недостаточная плавность хода как одиночных, так и прицепных ЛАТ при вывозке лесоматериалов по недостаточно обустроенным ЛД с заданными эксплуатационными скоростями приводит к их частым колебаниям, оказывающим нега- 
тивное воздействие различной степени на работоспособное состояние водителя, а также приводящих к возникновению неудобств при выполнении управления ЛАТ, ухудшающих производительность и способствующих возможному возникновению дорожно-транспортных происшествий. Ухудшение плавности хода, проявляющееся в увеличении колебаний в продольной, поперечной и вертикальной плоскостях ЛАТ, наблюдается при использовании для вывозки лесоматериалов ЛАТ, состоящего из двух прицепных звеньев, соединенных тягово-сцепным или седельно-сцепным устройствами. Наибольшее значение плавность хода оказывает на многоосные ЛАТ высокой проходимости, так как это эксплуатационное свойство изменяется в различных природно-климатических и дорожных условиях вывозки лесоматериалов и зависит от конструктивных особенностей их несущих систем. Отказ разработчиков новой техники от использования гидропневматических, пневматических, а также активных или полуактивных подвесок с динамическим регулированием не способствует улучшению плавности хода ЛАТ.

На эффективность функционирования ЛАТ оказывают существенное влияние потребительские качества, которые призваны удовлетворять потребностям лесозаготовителей в части стоимости, производительности, экономичности, надежности, безопасности эксплуатации и экологичности.

Эффективность функционирования современных ЛАТ при вывозке лесоматериалов по недостаточно обустроенным ЛД в большей степени зависит от надежности, отражающей изменения, протекающие в ЛАТ на протяжении всего его жизненного цикла и складывающиеся из надежности отдельных его структурных элементов. Изменение ресурса ЛАТ зависит от своевременной замены его деталей, надежность которых сокращается в результате длительной работы по причинам таких процессов, как износ, коррозия, старение материалов и т.д. Интенсивность изменения параметров работоспособности зависит от большого количества факторов, наиболее важными из которых являются: степень конструктивного совершенства, качество технологического процесса изготовления и производства, условия функционирования ЛАТ, полноты и качества выполнения регламентированных ТО и ТР, а также квалификация водителей. Повышение полной массы ЛАТ приводит к изменению режима его движения по ЛД, сопровождающегося увеличением нагрузок на его агрегаты и механизмы, а также сокращением их ресурса и надежности. Кроме этого снижение надежности ЛАТ сопровождается ухудшением экономических показателей, связанных с длительными простоями ЛАТ в ремонте при появлении внезапных отказов [14].

При использовании ЛАТ за пределами срока службы, затраты на поддержание его работоспособного состояния в сравнении с новым ЛАТ увеличивается в 2-3 раза, что также ведет к возрастанию количество вредных загрязняющих 
окружающую среду выбросов. Появление в таких ЛАТ отказов способствует ухудшению своевременности доставки лесоматериалов, повышению стоимости вывозки лесоматериалов, а также возможному возникновению дорожнотранспортных происшествий. На надежность ЛАТ также оказывает влияние приспособленность конструкции ЛАТ, его агрегата или узла к выполнению с минимальной трудоемкостью требуемых операций по ТО и ТР с целью поддержания долговечности и безотказности в рассматриваемых условиях эксплуатации.

В общем случае удобство использования ЛАТ, являющееся комплексным свойством, зависящим от его конструктивных особенностей, также оказывает влияние на достижение им высоких показателей эффективности. Удобство характеризуется маневренностью, плавностью хода, компактностью, удобством погрузки и разгрузки лесоматериалов, готовностью к движению, легкостью управления и запасом хода. Недостаточное удобство погрузочно-разгрузочных работ, выполняемых гидроманипулятором при вывозке лесоматериалов проявляется вследствие конструктивного несовершенства ЛАТ. К ней относится недостаточная погрузочная высота кузова ЛАТ, наличие или отсутствие гидроманипулятора, вибрационные нагрузки на водителя, шасси и кузов ЛАТ, имеющие место при недостаточной плавности хода и вызывающая повреждения и поломки кузова и шасси, а также способствующее повышению утомляемости водителя. Сложность управления ЛАТ повышается при неизбежном увеличении общего числа движений, выполняемых водителем при его управлении ЛАТ, неудовлетворительных условиях рабочего места водителя, часто завышенных усилий, необходимых для включения и выключения органов управления ЛАТ, неэффективной работы системы отопления и вентиляции кабины, а также отсутствии другого дополнительного оборудования, повышающего комфортные условия. Низкая готовность к движению характеризуется неприспособленностью ЛАТ за минимальный промежуток времени выполнять выезд с погрузочно-разгрузочного пункта для вывозки лесоматериалов потребителю.

Недостаточная безопасность ЛАТ при его движении в процессе вывозки лесоматериалов наблюдается при высокой интенсивности движения транспортных средств, высокой скорости движения ЛАТ, неудовлетворительном техническом состоянии и низкой надежности его тормозной системы. Неисправности в последней приводят к появлению отказов, которые из-за больших габаритных размеров и его значительной массы ЛАТ способствуют возникновению опасных ситуаций, связанных со складыванием и его опрокидыванием при набегании прицепа на лесовозный автомобиль. Безопасность ЛАТ также снижается вследствие несоответствия требований, предъявляемых к их тягово-сцепным и седельно-сцепным устройствам. Ухудшение наблюдается при неисправности или отсутствии в указанных кон- 
струкциях двойной фиксации от самопроизвольной расцепки прицепа или полуприцепа от лесовозного автомобиля, а также гасящих вибрационные нагрузки устройств. Положение усугубляется также отсутствием систем контроля за процессом с места водителя.

Экологичность также оказывает значительное влияние на эффективность функционирования ЛАТ. Наиболее важным показателем экологичности является безвредность ЛАТ, характеризуемая минимальными выбросами токсичных веществ в окружающую среду и величинами шумовых воздействий. При этом менее экологичными считаются такие ЛАТ, у которых больший расход топлива. Увеличение количества ЛАТ для выполнения заданного объема работ по вывозке лесоматериалов приводит к заметному повышению их негативного влияния на окружающую среду, последствия которых широки и многогранны, и затрагивают все сферы жизнедеятельности человека.

На эффективность функционирования ЛАТ оказывает влияние правильное определение транспортных, дорожных, климатических и нагрузочных условий ЛАТ. Трудные условия эксплуатации приводит к увеличению расходов на обеспечение исправного состояния ЛАТ по причине более интенсивного изменения его технического состояния и снижения надежности. Изменение почво-грунтовых условий рельефа местности приводит к снижению проходимости, и, следовательно, эффективности функционирования ЛАТ. Транспортные условия, предусматривающие вид, объем и расстояние вывозимых лесоматериалов, процессы их погрузки, разгрузки и вывозки, ТО, ТР и хранения ЛАТ, предопределяют выбор его типа и конструкции. Неправильное определение требуемого количества ЛАТ, их грузоподъемности не позволит осуществить вовремя вывозку заданного объема лесоматериалов, а также сократит их среднегодовой грузооборот.

Эффективность ЛАТ также существенно зависит от дорожных условий при их движении по недостаточно обустроенным временным ЛД, имеющим либо упрощенное дорожное покрытие, либо без него. При вывозке лесоматериалов вследствие дождей и гололеда, значительно снижающих сцепление ведущих колес с дорожным покрытием ЛД. В процессе эксплуатации ЛД происходит значительное изменение степени ровности ее покрытия, на ней появляются неровности и дефекты, которые оказывают влияние на такие технико-экономические показатели ЛАТ, как расход топлива, износ, срок службы, объем работ по ТО и ТР, межремонтные пробеги и др. Дорожные условия оказывают непосредственное влияние также на технико-эксплуатационные показатели работы ЛАТ, их технические характеристики и конструкцию. Сложные дорожные условия приводят к невозможности использования ЛАТ с низким коэффициентом сцепной массы, особенно в процессе его трогания с места после остановки на подъемах. От эксплуатационных показателей 
ЛД зависит как его пропускная способность, скорость, так и безопасность, допустимые осевые нагрузки на ЛАТ. Скорость движения ЛАТ также зависит от видимости на ЛД, ширины ее проезжей части, радиусов закруглений, уклонов и т.д. На ЛД в равнинной местности средние скорости движения ЛАТ могут быть наиболее высокими, так как видимость не ограничивается поворотами и переломами продольного профиля. Выполнение закруглений на ЛД заниженного радиуса приводит при движении ЛАТ к ухудшению их боковой устойчивости. Кроме этого при движении по неровностям и дефектам ЛД, ЛАТ расходует дополнительную энергию вследствие ударов колес о неровности ЛД, колебаний ЛАТ и лесоматериалов, которые гасятся подвеской ЛАТ. Следовательно экономия затрат лесозаготовительными предприятиями на обустройство ЛД оборачивается значительными более высокими затратами на эксплуатационные издержки ЛАТ [15].

Важным фактором, влияющим на эффективное использование ЛАТ, являются природно-климатические условия и сезонность работы лесозаготовительной и транспортной техники в течение календарного года. Очевидно, что существенные различия при эксплуатации ЛАТ в летний, зимний и переходные периоды года, накладывают свои особенности и которые заметно ограничивают потенциальные возможности этой техники. Не смотря на известное заметное потепление климата в последние десятилетия, и, в частности, в северных районах страны, где сосредоточены основные запасы леса, влияние низких температур на надежную работу агрегатов самого автомобиля и его технологического оборудования все же еще весьма значительно. При этом, в сочетании с имеющими место недостаточным качеством и своевременностью выполнения регламентированных работ по ТО и ТР, многие ответственные детали и узлы современных ЛАТ подвержены неоправданно повышенному износу, а часто и преждевременному выходу из строя. Аналогичная картина с эксплуатацией ЛАТ и в остальные периоды года. От природноклиматических условий также существенно зависит состояние покрытия ЛД, которое может быть влажным, заснеженным, обледенелым, а также зависит видимость на ЛД в дождь, снег, туман. Кроме этого избыточная влага, в том числе от многочисленных родников и грунтовых вод способствует снижению скорости ЛАТ, вследствие снижения надежности несущей способности ЛД из-за размыва ее дорожного полотна. Возможные оползни также создаю опасность для ЛАТ, а сильный ветер приводит к неустойчивости ЛАТ и возможной потере управления и к переворачиванию ЛАТ. Ограничение видимости из-за наличия тумана, дымки, пыли, смога или слепящего солнечного света также способствует снижению скорости ЛАТ и повышению опасности его столкновения, как со встречным транспортом, так и с возможными препятствиями [16, 17].

Нерациональное компонование ЛАТ, формирование прицепных звеньев, яв- 
ляется также причиной недостаточной эффективности функционирования ЛАТ в процессе транспортирования лесоматериалов. Усложнение организации вывозки лесоматериалов ЛАТ наблюдается при использовании для их компонования разномарочных лесовозных автомобилей и прицепов, имеющих различную грузоподъемность. Применение для вывозки лесоматериалов одиночных ЛАТ в сравнении с прицепными не позволяет: более полно использовать запас мощности его двигателя; повышать грузоподъемность; формировать прицепной ЛАТ большой грузоподъемности из-за наличного подвижного состава без существенного изменения его конструкции; легко разделять перевозимый груз лесоматериалов без перегрузки при необходимости его доставки в различные пункты назначения; уменьшить число водителей и ремонтных рабочих; повысить организацию транспортного процесса при оперативном и гибком управлении составом ЛАТ в зависимости от условий эксплуатации и возможности организации новых наиболее прогрессивных методов вывозки лесоматериалов; повышать производительность; значительно снижать расход топлива на тонну вывозимых лесоматериалов, сокращать расходы смазочных и других эксплуатационных материалов; уменьшать себестоимость вывозки лесоматериалов. Кроме этого стоимость одинаковых по грузоподъемности прицепных ЛАТ значительно ниже стоимости одиночных. Применение прицепных ЛАТ позволяет снизить капиталовложения в строительство зон полноценного гаражного и вне гаражного хранения подвижного состава, сократить удельные затраты на ТО и $\mathrm{TP}$, освободить значительное количество рабочих занятых как на эксплуатации, так и в ТО, и ТР, а также в ряде случаев использовать прицепной состав в качестве временного склада.

Выбор несоответствующей массы при подборе прицепного состава для ЛАТ, не позволит наиболее полно реализовать его массу и обеспечить максимальную рейсовую нагрузку при рациональном размещении лесоматериалов на нем. Нерациональное использование массы ЛАТ, заключающееся в его недогрузке приводит к неполной реализации его тяговых свойств, сцепной массы, снижению производительности при относительно невысоком расходе топлива и износе двигателя, а также к невозможности достижения ЛАТ оптимальной рейсовой нагрузки, при которой себестоимость вывозки $1 \mathrm{~m}^{3}$ лесоматериалов достигает минимального значения. Возможное превышение максимально разрешенной массы ЛАТ при вывозке лесоматериалов с целью достижения водителями и предпринимателями максимальной прибыли является причиной: возникновения опасных ситуаций на ЛД за счет возрастания риска опрокидывания ЛАТ из-за повышения его центра тяжести, уменьшения маневренности и увеличения тормозного пути; наложения штрафов на руководителей лесозаготовительных предприятий; уменьшения ресурса ходовой части и шин ЛАТ за счет увеличения износа его сцепления, коробки передач, раздаточной 
коробки и редукторов мостов [18].

Использование при вывозке лесоматериалов по недостаточно обустроенным ЛД ЛАТ с прицепами может ограничиваться по следующим причинам, связанным: со снижением ресурса тяговых лесовозных автомобилей или тягачей; с недостаточной проходимостью, с низкой удельной мощностью; с неудовлетворительной маневренностью, управляемостью и вписываемостью при прохождении профильных кривых и кривых в плане ЛД; с ограничением при движении задним ходом; с ухудшением процесса торможения в связи с запаздыванием срабатывания тормозных механизмов прицепных звеньев; с уводом прицепных звеньев на поворотах малого радиуса в связи с наличием прямой сцепки между первым и вторым комплектом; с затруднением в процессе разгрузки ЛАТ на одну разгрузочную площадку в связи с буксованием лесовозного тягача после разгрузки первого комплекта; с повышенной опасностью при разъездах с встречными ЛАТ и его обгонах из-за большой его длины.

Несоответствие структуры используемого автопарка ЛАТ по группам грузоподъемности типу вывозимых лесоматериалов, игнорирование при определении требуемого типажа ЛАТ осевых нагрузок на ЛД от одиночных и спаренных мостов ЛАТ, максимальной допустимой массы прицепа, полной нагрузки ЛАТ на ЛД, колесной формулы, количества осей прицепного состава, типа и мощности двигателя, а также долговечности ЛАТ приводит к существенному снижению эффективности его функционирования. Также неудовлетворение требований при компоновке ЛАТ, заключающихся в целенаправленном распределении его масс, обеспечивающих заданные пределы изменения центра тяжести в условиях эксплуатации, а также распределение нагрузок между несущими элементами ЛАТ, приводит к ухудшению его эффективности.

Рациональный выбор применяемой технологии организации транспортирования лесоматериалов ЛАТ, используемых методов погрузки лесоматериалов способствует повышению эффективности функционирования ЛАТ. От вида вывозимых лесоматериалов и его характеристик зависит выбор типа и состава ЛАТ. Среднесуточная потребность в ЛАТ и режим их работы зависят от конъюнктуры рынка, а также объема и стабильности вывозки лесоматериалов, потребность в которых в свою очередь может быть разовой, эпизодической, сезонной с месячной или квартальной неравномерностью, а режимы односменные, двух- и трех сменные. В зависимости от характеристик вывозимых лесоматериалов, а также дальности их вывозки, подразделяемой на вывозку лесоматериалов внутри одного лесозаготовительного предприятия, непосредственно во двор потребителю, а также межрайонные и межрегиональные перевозки, могут изменяться требования к габаритным, весовым параметрам и тягово-скоростным качествам ЛАТ. 
От выбора используемого способа погрузки и выгрузки лесоматериалов, который, может осуществляться с помощью гидроманипулятора, установленного на ЛАТ, специальными погрузочными средствами, а также с помощью использования сменных прицепов, полуприцепов и съемных контейнеров зависит время простоя ЛАТ на погрузочно-разгрузочной площадке. На эффективность функционирования ЛАТ значительное влияние оказывает правильность выбора вида маршрута вывозки лесоматериалов, а также формы организации их вывозки. Наиболее часто используемыми видами маршрутов являются маятниковый, обеспечивающий связь между одним отправителем и получателем, кольцевые, подразделяемые на развозные, сборные и сборно-разборные. При развозном кольцевом маршруте транспортная связь осуществляется между одним отправителем и несколькими получателями. Сборный кольцевой маршрут обеспечивает связь между одним получателем и несколькими отправителями. Различные комбинации из двух указанных выше разновидностей кольцевых маршрутов образуют сборно-разборный маршрут вывозки лесоматериалов.

Оптимальность организации эффективной работы ЛАТ на комбинированных маршрутах оказывает значительное влияние на транспортные издержки. Наибольшее использование при вывозке лесоматериалов ЛАТ нашли такие формы организации вывозки, как прямая, одноступенчатая и двухступенчатая. Применение двухступенчатой вывозки лесоматериалов, при которой на первой ступени лесоматериалы от лесосеки до перегрузочного пункта вывозятся более легкими ЛАТ, а на второй ступени от перегрузочного пункта до нижнего склада более тяжелыми ЛАТ существенно повышают затраты на транспортировку. Также вывозка лесоматериалов может осуществляться без разделения ЛАТ, с заменой лесовозного тягача или прицепного состава, сквозным способом, а также с использованием принципа тяговых плеч. Кроме этого, вывозка лесоматериалов может выполняться централизованным и децентрализованным способами, в зависимости от которых предъявляют ряд требований по используемым системам диспетчерской связи, а также оборудованию кабин ЛАТ средствами связи [19].

Эффективность вывозки лесоматериалов во многом зависит от совершенства применяемых технологий, а также от использования прогрессивных методов организации транспортного процесса. Правильный выбор используемой технологии позволяет сократить продолжительность времени вывозки лесоматериалов, ее трудоемкость за счет уменьшения числа выполняемых операций и этапов процесса вывозки. Кроме этого эффективность вывозки лесоматериалов ЛАТ ухудшается при: отказе от ночной загрузки ЛАТ, позволяющей избежать простои погрузочно-разгрузочных механизмов в ночное время; не использовании оборотных прицепов и полуприцепов, уменьшающих время простоя ЛАТ при выполнении 
погрузочно-разгрузочных операций; снижении коэффициента прямой перевалки лесоматериалов; не ритмичной подаче ЛАТ в перевалочный пункт. Также неоптимальная организация процесса вывозки лесоматериалов, не обеспечивающая минимальную протяженность его во времени и обслуживаемой территории и наиболее полное использование потенциальных энергетических параметров ЛАТ не позволит сократить расход топлива ЛАТ и повысить его эффективность [20].

Эффективность процесса транспортирования лесоматериалов потребителям ухудшается при низком уровне квалификации водителей и ремонтнообслуживающего персонала. На безопасность функционирования ЛАТ также влияет психофизиологическое состояние их водителей, выполняющих основную функцию лесотранспортной системы, заключающуюся в вывозке лесоматериалов. Данное состояние характеризуется вниманием, утомляемостью, эмоциональностью водителей, а также их изменчивостью с течением времени, зависящей от особенностей и возможностей их организма воспринимать неудобства при движении ЛАТ по недостаточно обустроенным ЛД в сложных природно-климатических условиях.

От квалификации водителя во многом зависит текущее техническое состояние и содержание ЛАТ, умение правильно выбирать его оптимальный тяговый режим, тактику движения по ЛД с оценкой дорожной ситуации, а также быстрота и точность реакции водителя на изменение условий движения ЛАТ. Чем ниже квалификация водителя, тем ниже уровень знаний ЛАТ, режимов и правил его эксплуатации, и, соответственно, тем меньших производственных показателей он может достигнуть, а также больше вероятность возникновения дорожнотранспортных происшествий.

Безопасное движение ЛАТ по ЛД также связано с дисциплинированностью и ответственностью водителей, которые имеют связь с их социальными особенностями, интеллектуальным и культурным уровнем развития. Низкая устойчивость, переключаемость внимания, недостаточная реакция водителя, заключающаяся в долгой оценке получаемой водителем ЛАТ информации о дорожной обстановке, медленное воздействие на органы управления ЛАТ, неправильно принимаемые решения в процессе управления ЛАТ на высоких скоростях в сложных быстро меняющихся дорожных и природно-климатических условиях снижают безопасность и эффективность функционирования ЛАТ. Также на работоспособность водителя ЛАТ, как участника движения существенное влияние оказывают климат и погода, которые характеризуются разнообразными сочетаниями температуры, влажности, движения воздуха и давления, солнечной радиацией и другими факторами. Существенное влияние на эффективность использования ЛАТ оказывает полноценная организация системы безопасности на всех стадиях транспортного процесса. Немаловажно также все еще практически полное отсутствие системы оперативного опо- 
вещения водителя ЛАТ в режиме текущего времени о состоянии и возможностях ЛД на маршрутах движения [21].

От состояния ремонтного персонала, являющегося подсистемой ТО и ТР ЛАТ и характеризующейся уровнем обеспеченности, квалификацией, моральной и материальной заинтересованностью, зависит своевременность, качество ремонта ЛАТ, и, следовательно, его эффективность функционирования. На эффективность выполнения ремонтным персоналом ТО и ТР оказывают влияние: уровень их квалификации, степень обеспеченности ремонтным оборудованием и инструментом, их производительность, обеспеченность запасными частями и материалами, степень использования рабочего времени поста, среднесписочное количество ЛАТ в парке, среднее количество рабочих на посту, объем входящего потока ЛАТ, а также сменность работы.

Существенное влияние на изменение эффективности работы ЛАТ при вывозке лесоматериалов оказывает его техническое состояние, а также технологии и уровень качества организации ТО и ТР. Эффективность ЛАТ, функционирующего в сложных дорожных условиях ухудшается при отсутствии использования современного диагностического, а также ремонтного передвижного и стационарного оборудования. Кроме этого, значительное влияние на эффективность функционирования ЛАТ оказывает их техническое состояние и качество организации ТО и ТР. Техническое состояние ЛАТ определяется его потенциальными физическими свойствами и степенью полноты использования в сложных природно-климатических и дорожных условиях эксплуатации. Ухудшение технического состояния ЛАТ, сокращение их выпуска на линию, повышение потерь рабочего времени в процессе выполнения погрузочно-разгрузочных работ не позволит увеличить производительность и снизить стоимость вывозки лесоматериалов в трудных условиях эксплуатации ЛАТ [22].

В трудных условиях эксплуатации физический износ ЛАТ ухудшает его техническое состояние и приводит к снижению уровня безопасности процесса вывозки лесоматериалов, и росту транспортных издержек. Использование для вывозки лесоматериалов ЛАТ за пределами срока службы требует на поддержание его работоспособного состояния в 2-3 раза больше затрат, чем в начале эксплуатации, а также приводит к повышению вредных выбросов в окружающую среду. Кроме этого, частые отказы таких ЛАТ нарушают своевременность его доставки до необходимого пункта погрузки-разгрузки, а также являются причинами возникновения дорожнотранспортных происшествий. Своевременность выполнения ТО и ТР ЛАТ также оказывает влияние на эффективность его функционирования, так как позволяет во время устранить дефекты и износы в его агрегатах и узлах, сократить простои ЛАТ из-за технических неисправностей, увеличить сменную выработку, а также улуч- 
шить весь комплекс технико-экономических показателей. Несвоевременность выполнения диагностических работ ЛАТ не позволит оперативно выявить и устранить причины имеющихся неисправностей, спрогнозировать изменения их технического состояния для определения предлагаемого момента отказа или для его предупреждения, обеспечить более полное использование ресурса, сократить расход запасных частей и материальных средств, что ведет к снижению их надежности и экономичности использования.

Техническое состояние ЛАТ и его эффективность функционирования, определяющие их производительность и снижение себестоимости процесса вывозки лесоматериалов, также зависят от организации, технологии и качества выполнения работ, связанных с диагностированием ЛАТ, их ТО и ТР. Кроме этого, уровень качества выполнения работ по ТО и ТР ЛАТ с минимальными затратами труда, энергии и материалов во многом зависит от того, насколько хорошо продуманы и отработаны в исходной конструкции ЛАТ возможности замены его недолговечных деталей [23].

На эффективность организации ТО и ТР ЛАТ значительное влияние оказывает процесс управления своевременной доставкой запасных агрегатов, частей и расходных материалов. В современных условиях в связи с существенным обновлением парка ЛАТ, занятых в процессе вывозки лесоматериалов, возникает необходимость обеспечения ЛАТ оригинальными агрегатами, запасными частями и комплектующими, которые можно заказать только в специализированных центрах или у дилеров фирм производителей. Отсутствие логистической поддержки с централизованной организацией поставок качественных запасных частей и материалов на склады лесозаготовительных предприятий для всего разномарочного парка ЛАТ с полной номенклатурой требуемых деталей, оказывает значительное влияние на продолжительность простоев ЛАТ при подготовке и выполнении ТО и ТР.

Тяжелые условия эксплуатации ЛАТ приводят к тому, что зачастую плановое проведение ТО и ТР их агрегатов становится экономически нецелесообразным, поэтому вышедшие из строя агрегаты подвергаются дальнейшему агрегатному ремонту, что естественно увеличивает издержки на содержание ЛАТ. Прогрессивные технологии восстановления деталей, используемые при агрегатном ремонте ЛАТ, оказывают существенное влияние на дальнейшее эффективное функционирование ЛАТ. Снижение эффективности агрегатного ремонта наблюдается при: несоответствии комплектности, основных параметров деталей, агрегатов в сборе в технической документации; повышенных расходах материалов, трудовых и энергетических ресурсов, затрачиваемых на восстановление деталей агрегатов; невозможности достижения 80 \%-ной послеремонтной наработки агрегатов ЛАТ от наработки новых; низкой долговечности отремонтированных деталей и агрегатов ЛАТ. 


\section{Выводы}

В результате выполненного анализа основных причин недостаточной эффективности функционирования ЛАТ, которые непосредственно влияют на процесс вывозки лесоматериалов, а также учитывая мировой научнотехнический прогресс в автомобильной отрасли и существующие направления развития ЛАТ, можно выделить основные пути повышения эффективности, которые можно реализовать на всех стадиях их жизненного цикла (рис. 1).

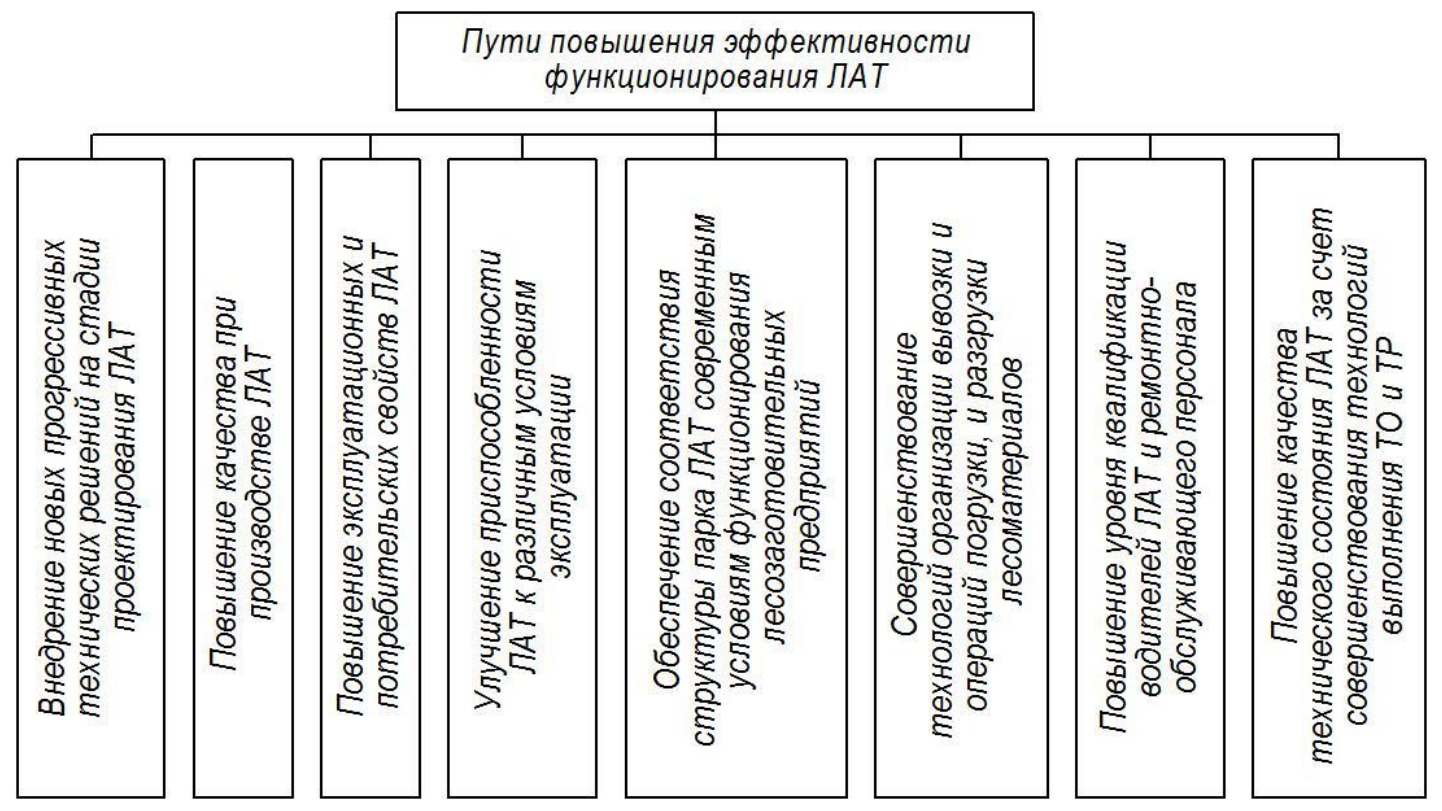

Рисунок 1 - Основные пути повышения эффективности ЛАТ

В настоящее время научные изыскания авторов связаны со снижением энергозатрат при погрузке, разгрузке и вывозке лесоматериалов ЛАТ, оснащенным гидроманипуляторами, и имеющим недостаточную приспособленность работы в сложных дорожных и природно-климатических условиях. Одним из перспективных направлений снижения энергозатрат ЛАТ в процессе вывозки лесоматериалов в таких условиях, является использование в его конструкции энергосберегающих устройств, основанных на рекуперации различных видов энергии. В связи с этим для повышения эффективности функционирования ЛАТ, авторами ведутся научные исследования по разработке и реализации для них перспективных научнотехнических решений, позволяющих улучшить его топливную экономичность, производительность, надежность, снизить материалоемкость, а также повысить другие показатели его эксплуатационных и потребительских свойств. Среди уже предложенных авторами технических решений, наибольший интерес представляют рекуперативные гидроприводы для различных случаев компонования ЛАТ, такие как: устройства, используемые в гидроприводах для аккумулирования и преобразо- 
вания энергии сжатого воздуха в энергию рабочей жидкости; модульные подвески; тягово-сцепные устройства; седельно-сцепные устройства; кониковые устройства лесовозных площадок.

Для комплексного обоснования и оценки предложенных перспективных научно-технических решений необходимо выполнить оптимизацию их основных рабочих и конструктивных параметров с учетом технологических особенностей их функционирования в процессе погрузки, разгрузки и движении ЛАТ при вывозке лесоматериалов в сложных, противоречивых и быстро изменяющихся дорожных и природно-климатических условиях. Для оптимизации основных рабочих и конструктивных параметров перспективных научно-технических решений, реализованных в конструкциях ЛАТ, требуется разработка математических моделей, алгоритмов и на их основе программ для ЭВМ. Эти математические модели и программы для ЭВМ в общем случае должны позволять:

- моделировать различные режимы движение ЛАТ по случайной неровной опорной поверхности, характерные для ЛД с целью определения колебаний между прицепными звеньями, а также расчета рекуперируемой мощности, получаемой от гидромоторов колес ЛАТ, его гидропневматических рекуперативных подвесок модульного типа, соответствующих рекуперативных тягово-сцепных и седельносцепных устройств, а также в рекуперативном кониковом устройстве лесовозной площадки;

- моделировать работу рекуперативного гидропривода манипулятора в процессе погрузки и разгрузки лесоматериалов, с целью оценки его эффективности в различных режимах работы, а также исследования при этом влияния параметров системы рекуперации на изменение рекуперируемой мощности;

- моделировать различные режимы движение ЛАТ, оснащенных различными подвесками модульной конструкции по опорной поверхности ЛД с заданными параметрами неровностей с целью исследования влияния эксплуатационных параметров ЛАТ на плавность хода и показатели эффективности при его движении по ЛД;

- моделировать работу рекуперативного гидропривода ЛАТ, оснащенного системами аккумулирования и преобразования энергии сжатого воздуха, с целью определения показателей их эффективности, расчета тепловых потерь при преобразовании энергии, а также нахождения оптимальных конструктивных и технологических параметров их основных элементов.

Кроме этого, разрабатываемые программы для ЭВМ функционально должны учитывать изменение: геометрических, кинематических и динамических параметров ЛАТ; технологических параметров гидроманипулятора ЛАТ с системой рекуперации энергии; геометрических и весовых параметров лесома- 
териалов: параметров рельефа опорной поверхности ЛД; условий и особенностей движения ЛАТ; параметров исследуемого рекуперативного устройства, подвесок модульного типа; геометрических и теплофизических характеристик элементов пневмо- и гидросистемы устройства аккумулирования энергии сжатого воздуха.

По результатами теоретических исследований полученных на основе разработки математических моделей, программ для ЭВМ, получения выявленных закономерностей функциональных связей между рабочими и конструктивными параметрами предлагаемых перспективных научно-технических решений, реализованных в конструкциях ЛАТ, нахождения количественных показателей их эффективности, а также аналитических зависимостей режимов их работы от основных геометрических и кинематических параметров, требуется разработка методик и проведение углубленных экспериментальных исследований с опытнопроизводственной проверкой натурных образцов с дальнейшей разработкой рекомендаций по их рациональному применению.

Экспериментальные исследования в процессе проверки основных зависимостей, полученных в процессе моделирования, планируется выполнить на специально сконструированных для этих целей стендах в лабораторных и полевых условиях. Для фиксирования исследуемых параметров предлагаемых научно-технических решений, реализованных в ЛАТ планируется использование электротензометрического метода с беспроводной передачей данных и обработкой на ЭВМ получаемых результатов методами математической статистики в режиме реального времени, а также применение метода скоростной видеосъемки цифровыми бортовыми и стационарными камерами с компьютерным распознаванием образов и обработкой изображений.

\section{СПИСОК ЛИТЕРАТУРЫ}

1 Технология и оборудование лесосечных работ. Режим доступа : https://proderevo.net/industries/wooden-logging/tekhnologii-lesozagotovok/tekhnologiya-i-oborudovanie-lesosechnykn-rabot.html. - Загл. с экрана.

2 Никонов, В. О. Анализ конструктивных особенностей седельносцепных устройств тягачей с полуприцепами / В. О. Никонов, В. И. Посметьев, Т. Н. Фомин // Воронежский научно-технический вестник. - 2019. - Т. 1, № 1 (27). - C. 20-32.

3 Посметьев, В. И. Анализ эффективности конструкций лесовозных площадок, устанавливаемых на лесовозных тягачах с прицепами-роспусками / В. И. Посметьев, В. О. Никонов, А. В. Авдюхин, А. Е. Матяшов // Воронежский 
научно-технический вестник. - 2020. - Т. 1, № 1 (31). - С. 40-57.

4 Никонов, В. О. Анализ условий и оценка эффективности использования лесовозных автомобилей в Российской Федерации на современном этапе ее развития / В. О. Никонов, В. И. Посметьев // Воронежский научно-технический вестник. - 2020. - Т. 2, № 2 (32). - С. 49-73.

5 Никонов, В. О. Оценка состояния лесовозных дорог в РФ, используемых для вывозки лесоматериалов автомобильным транспортом / В. О. Никонов, В. И. Посметьев, А. В. Авдюхин // Воронежский научно-технический вестник. - 2020. Т. 2, № 2 (32). - С. 74-84.

6 Кондрашова, Е. В. Сравнительная оценка надежности грузовых автомобилей / Е. В. Кондрашова, А. В. Скрыпников, К. А. Яковлев, Т. В. Скворцова, В. Г. Козлов // Труды ГОСНИТИ, 2016, Т. 123. - С. 61-67.

7 Александров, В. А. Основы проектирования лесозаготовительных машин и оборудования / В. А. Александров, Я. И. Шестаков, Н. Р. Шоль, И. Н. Багаутдинов // учеб. пособие. - Ухта, 2007. - 283 с.

8 Антимонов, А. М. Основы технологии машиностроения : учебник / А. М. Антимонов. - Екатеринбург : Изд-во Урал. ун-та, 2017. - 176 с.

9 Скрыпников, А. В. Комплекс «водитель-автомобиль-дорога-среда» как двухуровневая децентрализованная система обслуживания / А. В. Скрыпников, Е. В. Чернышова, М. А. Абасов, П. В. Тихомиров // Современные наукоемкие технологии, 2019, № 5. - С. 81-87.

10 Козлов, В. Г. Анализ влияния погодно-климатических факторов на системы комплекса водитель-автомобиль-дорога-среда / В. Г. Козлов, А. В. Скрыпников, М. А. Абасов, В. В. Никитин, В. В. Сенцов // Инновационные технологии и технические средства для АПК : материалы международной научнопрактической конференции молодых ученых и специалистов, 2018. - С. 324-331.

11 Курьянов, В. К. Разработка методики оценки профессионального мастерства водителей лесовозных автотранспортных средств / В. К. Курьянов, Е. В. Кондрашова, А. Ю. Чувенко, М. А. Карпов // Депонированная рукопись № 53B2010 28.01.2010. - $26 \mathrm{c}$.

12 Никулин, М. А. Современное состояние и перспективы развития топливной экономичности поршневых двигателей внутреннего сгорания / М. А. Никулин, В. И. Посметьев, В. О. Никонов // Воронежский научно-технический вестник. - 2017. - Т. 2, № 2 (20). - С. 16-22.

13 Вашуткин, А. С. Улучшение эксплуатационных свойств тормозной системы лесотранспортных машин / А. С. Вашуткин // автореферат дисс. на соиск. 
ученой степени к. т. н., Архангельск, 2012.

14 Белокуров, В. П. Оценка показателей надежности лесовозных автотранспортных средств / В. П. Белокуров, К. А. Кучув, Э. Н. Бусарин // Научный журнал КубГАУ, № 77(03), 2012. - 10 с.

15 Афоничев, Д. Н. Моделирование движения автопоезда, оснащенного управляемой пневматической подвеской на поворотах / Д. Н. Афоничев, Д. С. Любавский // Техника в сельском хозяйстве, 2012, № 4. - С. 23-25.

16 Коточигов, М. В. Влияние климатических факторов на транспорт леса / М. В. Коточигов / Актуальные направления научных исследований XXI века : теория и практика. - Том 2, № 5 ч. 4, 2014. - С. 162-166.

17 Горбунов, А. А. К вопросу увеличения срока службы работы лесовозного автомобильного транспорта в суровых климатических условиях / А. А. Горбунов, А. М. Бургонутдинов, О. Н. Бурмистрова, О. М. Тимохова // Фундаментальные исследования, 2015, № 2-10. - С. 2092-2098.

18 Будалин, С. В. Эффективная эксплуатация лесовозных автопоездов на основе разрешенной максимальной грузоподъемности / С. В. Будалин, С. В. Никулин // Лесной Вестник, 6, 2016. - С. 116-121.

19 Колядин, П. А. Состояние и перспективы совершенствования встроенной системы диагностирования автомобиля / П. А. Колядин, И. И. Бойков, В. И. Посметьев, В. О. Никонов // Воронежский научно-технический вестник. - 2017. Т. 1, № 1 (19). - С. 11-19.

20 Сушков, С. И. Принципы и методы оптимизации транспортно-грузовых процессов на автомобильном транспорте / С. И. Сушков, А. В. Лисов // Воронежский научно-технический вестник, 2013. Т. 2, № 2(4). - С. 18-22.

21 Козлов, В. Г. Методы, модели и алгоритмы проектирования лесовозных автомобильных дорог с учетом влияния климата и погоды на условия движения / В. Г. Козлов // дисс. на соиск. уч. степ. д. т. н., Воронеж 2017. -406 с.

22 Смирнов, М. Ю. Рациональные способы и параметры загрузки автомобильных поездов на вывозке лесоматериалов / М. Ю. Смирнов // дисс. на соискание ученой степени доктора техн. наук, Йошкор-Ола, 2011. - 398 с.

23 Бурмистров, В. А. Совершенствование организации технического обслуживания, ремонта и эксплуатации лесотранспортных машин / В. А. Бурмистров // 05.21.01, дисс. на соиск. уч. ст. к. т. н., Ухта, 2013. 